Hessling Herrera, F.D. Derecho a la comunicación, periodismo e interés público: de la OC-5/85 a los problemas éticos actuales. Derecho y Ciencias Sociales. Noviembre 2020 - Abril 2021. No 24 .Pgs 58 -78. ISSN 1852-2971. Instituto de Cultura Jurídica y Maestría en Sociología Jurídica. Facultad de Ciencias Jurídicas y Sociales. Universidad Nacional de La Plata. Argentina.

\title{
Derecho a la comunicación, periodismo e interés público: de la OC-5/85 a los problemas éticos actuales
}

\author{
Communication rights, journalism and public interest: from AO-5/85 to current ethical \\ problems
}

Franco David Hessling Herrera

\section{Resumen}

El presente artículo hace un recorrido por los orígenes de la libertad de expresión, su consagración como derecho humano y su vínculo con el derecho a la comunicación. A partir de ello se toman las interpretaciones de la doctrina del SIDH, signadas por la OC-5/85 de la Corte IDH, para hacer una triangulación analítica entre libertad de expresión, periodismo e interés público, a la luz de los flujos comunicacionales contemporáneos. En función de ese análisis se arriba a la conclusión de que se hace imprescindible una actualización doctrinaria en el SIDH, tanto como una reformulación de los deberes y coberturas jurídicas que circundan al ejercicio periodístico.

Palabras clave: Derecho a la comunicación, Libertad de expresión, Periodismo, Interés público.

\begin{abstract}
This article reviews the origins of freedom of speech, its consecration as a human right and its link with the right of communication. Based on this, it takes the interpretations of the IASHR doctrine, as expressed in the Advisory Opinion 5/85 of the IHR Court for an analytical triangulation between freedom of expression, journalism and public interest, in the light of contemporary communication flows. This analysis leads to the conclusion that it is essential to update the doctrine of the IASHR, as well as to reformulate the duties and legal coverage surrounding the practice of journalism.
\end{abstract}

Keywords: Communication rights, Freedom of expression, Journalism, Public interest.

\footnotetext{
- Licenciado en Ciencias de la Comunicación y pronto a obtener su título de Especialista en Derechos Humanos. Trabaja como docente de nivel medio y superior, en este último en las materias Comprensión y Producción de Textos y Antropología Económica. Es becario doctoral de Conicet con el tema políticas públicas, documentos jurídicos y discursos mediáticos vinculados a la energía. Trabaja como periodista gráfico desde los 21 años, actualmente es columnista en un diario de circulación provincial, Punto Uno. Ha publicado el ensayo "La Virgen del Cerro de Salta, refundar el mito" (Dunken, 2019) y el libro de cuentos "Gualicho contra la voluntad de poseer" (La Aparecida, 2020). francodavidhess@gmail.com
} 
Hessling Herrera, F.D. Derecho a la comunicación, periodismo e interés público: de la OC-5/85 a los problemas éticos actuales. Derecho y Ciencias Sociales. Noviembre 2020 - Abril 2021. No 24 .Pgs 58 -78. ISSN 1852-2971. Instituto de Cultura Jurídica y Maestría en Sociología Jurídica. Facultad de Ciencias Jurídicas y Sociales. Universidad Nacional de La Plata. Argentina.

\section{Derecho a la comunicación, periodismo e interés público: de la OC-5/85 a los problemas éticos actuales}

Franco David Hessling Herrera

\section{De la inviolabilidad parlamentaria al libre mercado de ideas}

En primer lugar conviene detenerse en la genealogía que antecede a la idea de "derecho a la comunicación” que proviene de la tradición liberal anglosajona de pensamiento y se inició con las necesidades políticas acaecidas en la flamante monarquía parlamentaria inglesa del siglo XVII. En ese entonces, la idea de "inviolabilidad parlamentaria" -lo que hoy se conoce como fueros- introdujo las primeras argumentaciones al respecto de la libertad de expresión para referirse a la forma en que podían manifestarse los flamantes legisladores del gobierno.

De ese antecedente, que podríamos llamar la forma política de la LdE puesto que se dio en el marco de la nueva forma de gobierno, se pasa a las formas económicas que circundaron la discusión y que tuvieron su apogeo cuando la imprenta se introdujo en la sociedad inglesa. Pensadores como Milton y Looke (citados por Climent Gallart, 2016) discutieron contra la regulación a las formas de imprenta secular, el segundo de los cuales asegura que no debe haber censura de ningún tipo ya que la imprenta es una industria nueva y que promete grandes réditos. Tiempo después, la LdE es recogida como idea en textos de John Stuart Mill (2010), quien en su famoso ensayo Sobre la libertad hace una vinculación -quizá la más acabada que se conozca en términos filosóficos- entre el liberalismo y el individualismo, y en particular sobre lo que por entonces llamó “libertad de pensamiento y de opinión”. En los Estados Unidos, Jefferson será uno de los principales defensores de la Libertad de expresión, sentando las bases para asimilarla con la libertad de prensa, y entendiendo a las mismas como fundamentos centrales de una sociedad democrática.

Cruzando el Atlántico también pero ya a principios del siglo XX son diferentes jueces del máximo tribunal norteamericano, Brandeis y Holmes entre los más destacados (Climent Gallart, ibidem), quienes recogen la idea de Libertad de expresión para abordar la regulación de las empresas periodísticas. En ese estadío de la discusión se asimila libertad de expresión a libertad de prensa. Holmes, por ejemplo, para hacer su defensa de la libertad de expresión habla de "libre mercado de ideas". 
Hessling Herrera, F.D. Derecho a la comunicación, periodismo e interés público: de la OC-5/85 a los problemas éticos actuales. Derecho y Ciencias Sociales. Noviembre 2020 - Abril 2021. No 24 .Pgs 58 -78. ISSN 1852-2971. Instituto de Cultura Jurídica y Maestría en Sociología Jurídica. Facultad de Ciencias Jurídicas y Sociales. Universidad Nacional de La Plata. Argentina.

\section{Libertad de expresión como derecho humano}

La consagración de la libertad de expresión como derecho humano se dio en la Declaración Universal de Derechos del Hombre, que se formalizó el 10 de diciembre de 1948 en París ${ }^{1}$. El debate para volcar esa Declaración en un instrumento más operativo a nivel jurídico, como un Pacto, estuvo surcado por el contexto de Guerra Fría. Finalmente fueron dos pactos y se concretaron prácticamente veinte años después de la Declaración: el Pacto de Derechos Civiles y Políticos y el Pacto de Derechos Económicos, Sociales y Culturales.

Antes de los pactos, cuando apenas se había formado la ONU, se le encomendó al Consejo Económico y Social que trabajara con una declaración de principios, y éste a su vez le encomendó a la Comisión de Derechos Humanos que elaborará un anteproyecto de carta de derechos humanos. En la comisión de redacción y corrección del documento que luego sería la Declaración de 1948 hubo predominancia de estados de la tradición liberal occidental, tal cual lo demuestra el propio sitio oficial de la ONU, en el que se relata que el Comité de Redacción estuvo encabezado por Eleanor Roosevelt, viuda del presidente estadounidense Franklin D. Roosevelt.

La preeminencia de estados con sesgo liberal en la comisión redactora hizo que la libertad de expresión se hiciera explícita ya en aquella Declaración de 1948. En el artículo 19 se consigna: "Todo individuo tiene derecho a la libertad de opinión y de expresión; este derecho incluye el de no ser molestado a causa de sus opiniones, el de investigar y recibir informaciones y opiniones, y el de difundirlas, sin limitación de fronteras, por cualquier medio de expresión". Esa definición estuvo influenciada por toda la tradición liberal anglosajona, especialmente por las últimas elaboraciones doctrinarias que aceptaban que debían circular ideas de toda índole, sin consideración de fronteras, ya sea oralmente, por escrito o en forma impresa o artística, o por cualquier otro medio. La perspectiva que había quedado plasmada por los jueces disidentes del máximo tribunal norteamericano, por ejemplo, en los casos Abrams vs. United States y Whitney vs. California.

Como si hicieran falta más argumentos para dejar sentado que la libertad de expresión se insertó en el Sistema Universal de Derechos Humanos desde la tradición liberal, especialmente la anglosajona, la enunciación del derecho aparece en el Pacto Internacional de Derechos Civiles

\footnotetext{
${ }^{1}$ Se formalizó a través de la Resolución 217 A (III) de la Asamblea General de las Naciones Unidas.
} 
Hessling Herrera, F.D. Derecho a la comunicación, periodismo e interés público: de la OC-5/85 a los problemas éticos actuales. Derecho y Ciencias Sociales. Noviembre 2020 - Abril 2021. N 24 .Pgs 58 -78. ISSN 1852-2971. Instituto de Cultura Jurídica y Maestría en Sociología Jurídica. Facultad de Ciencias Jurídicas y Sociales. Universidad Nacional de La Plata. Argentina.

y Políticos (ICCPR por su sigla en inglés), aquel que expresó la voluntad de la superpotencia de Occidente en aquellos años de Guerra Fría.

Antes de ello, la Convención Europea de Derechos Humanos (1950) recogió la libertad de expresión como derecho y le imprimió algunas de esas dimensiones que la Declaración de 1948 no había apuntado. Además, el artículo 10 de la Convención Europea introdujo aspectos que el sistema universal, con hegemonía del liberalismo norteamericano, no establecía, como la posibilidad de que los estados intervengan en el otorgamiento de permisos para usar el éter o imprimir periódicos, tanto como la importancia de "recibir" información como complemento del mismo derecho que defiende la expresión y difusión. Así se deduce del primer párrafo de ese artículo, al tiempo que en el segundo ya se apuntalan los aspectos que luego, en 1966, el ICCPR vendría a ampliar.

Justamente, en su artículo decimonoveno el ICCPR plantea una ampliación significativa de los alcances de la libertad de expresión, ya que establece "deberes y responsabilidades especiales" y eventuales situaciones en las que se podrían imponer "ciertas restricciones". En este artículo del ICCPR se hallan implícitamente los principios de legalidad y proporcionalidad ${ }^{2}$. Por otra parte, se hace diáfana una de las tensiones que marca los alcances de la libertad de expresión: el contrapeso con el derecho al honor y a la intimidad.

\section{Libertad de Expresiónen el Sistema Interamericano: cimientos dados por la OC-5/85}

Una veintena de años después de que la ONU estableciera ese plexo de normas de rango internacional, la Organización de Estados Americanos (OEA) celebró la Convención Americana sobre Derechos Humanos, sellada el 22 de noviembre de 1969 en San José de Costa Rica, país que actualmente es sede de la Corte Interamericana de Derechos Humanos (Corte IDH) (Faundez Ledesma, 2003). Ese instrumento fue ratificado por Argentina recién en marzo de 1984, sin hacer salvedades y reconociendo por "tiempo indefinido" la competencia de la Comisión y de la Corte interamericanas creadas luego del pacto firmado en Costa Rica. Éste y otros tratados, entre ellos los anteriormente citados -salvo por la Convención Europea-, forman parte del bloque constitucional argentino desde la reforma de 1994.

En dicha Convención se hace la más amplia mención a la libertad de expresión (Faundez Ledesma, 2004) que se ha planteado hasta el momento en algún instrumento internacional. Entre otras cosas, en el Pacto de San José de Costa Rica se proscriben no sólo situaciones de

\footnotetext{
${ }^{2}$ En referencia a los mecanismos que luego se fueron acordando para aceptar en qué ocasiones una limitación a la LdE constituye una restricción justificada.
} 
Hessling Herrera, F.D. Derecho a la comunicación, periodismo e interés público: de la OC-5/85 a los problemas éticos actuales. Derecho y Ciencias Sociales. Noviembre 2020 - Abril 2021. No 24 .Pgs 58 -78. ISSN 1852-2971. Instituto de Cultura Jurídica y Maestría en Sociología Jurídica. Facultad de Ciencias Jurídicas y Sociales. Universidad Nacional de La Plata. Argentina.

censura previa, sino también vías de censura indirecta, que pueden tener que ver con el accionar de un Estado o de "particulares", como las empresas de medios (artículo 13 de la Convención Americana).

En este artículo se añade también que:

Los espectáculos públicos pueden ser sometidos por la ley a censura previa con el exclusivo objeto de regular el acceso a ellos para la protección moral de la infancia y la adolescencia (...). Estará prohibida por la ley toda propaganda en favor de la guerra y toda apología del odio nacional, racial o religioso que constituyan incitaciones a la violencia o cualquier otra acción ilegal similar contra cualquier persona o grupo de personas, por ningún motivo, inclusive los de raza, color, religión, idioma u origen nacional.

La violencia simbólica contra la mujer, que en Argentina está legislada en el artículo quinto de la Ley 26.485 podría encuadrarse en una forma de odio y por eso merece especial mención (Federici, 2020). La misoginia, si bien no está explícita en este ni en ningún otro de los instrumentos de derechos humanos que hemos analizado, también representa una incitación a la violencia. Por lo tanto, ese tipo de expresiones también deberían ser limitadas si se hace una interpretación ampliada de las pautas establecidas por el artículo 13 de la Convención.

De igual modo, además se añade otro artículo que resulta fundamental porque habilita una instancia de resolución práctica de conflictos entre libertad de expresión y derecho al honor (art. 11 del mismo instrumento). Se trata del derecho a réplica, contenido en el artículo 14:

1. Toda persona afectada por informaciones inexactas o agraviantes emitidas en su perjuicio a través de medios de difusión legalmente reglamentados y que se dirijan al público en general, tiene derecho a efectuar por el mismo órgano de difusión su rectificación o respuesta en las condiciones que establezca la ley.

2. En ningún caso la rectificación o la respuesta eximirán de las otras responsabilidades legales en que se hubiese incurrido.

3. Para la efectiva protección de la honra y la reputación, toda publicación o empresa periodística, cinematográfica, de radio o televisión tendrá una persona responsable que no esté protegida por inmunidades ni disponga de fuero especial. 
Hessling Herrera, F.D. Derecho a la comunicación, periodismo e interés público: de la OC-5/85 a los problemas éticos actuales. Derecho y Ciencias Sociales. Noviembre 2020 - Abril 2021. No 24 .Pgs 58 -78. ISSN 1852-2971. Instituto de Cultura Jurídica y Maestría en Sociología Jurídica. Facultad de Ciencias Jurídicas y Sociales. Universidad Nacional de La Plata. Argentina.

A partir de ello es que muchos autores señalan al SIDH como aquel que le dio el más amplio abordaje (Loreti y Lozano, 2014). Tal vez eso se deba a la situación particular de los países de la región, tal como testimonia el ex Juez de la Corte IDH, Pedro Nikken, quien formó parte de los magistrados que emitieron la Opinión Consultiva de 1985 (OC-5/85) sobre la colegiación obligatoria de periodistas, reconocida como la primera interpretación desarrollada sobre el artículo 13 del Pacto de San José de Costa Rica. "La libertad de expresión es uno de los derechos más ultrajados por la democracia latinoamericana, por lo tanto, pensamos que era una buena ocasión para fijar un estándar sobre esa relación radical que existe entre libertad de expresión y la democracia", señala Nikken (en informe de la OEA Libertad de expresión: A 30 años de la Opinión Consultiva sobre la colegiación de periodistas, 2017).

La OC-5/85 es ineludible en lo que a la relación entre libertad de expresión, periodismo e interés público se refiere, tal cual lo plantea la propia Opinión Consultiva en su párrafo 50:

El análisis anterior del artículo 13 evidencia el altísimo valor que la Convención da a la libertad de expresión. La comparación hecha entre el artículo 13 y las disposiciones relevantes de la Convención Europea (artículo 10) y del Pacto (artículo 19) demuestra claramente que las garantías de la libertad de expresión contenidas en la Convención Americana fueron diseñadas para ser las más generosas y para reducir al mínimum las restricciones a la libre circulación de las ideas.

Y ratifican esa apreciación Loreti y Lozano en el Prefacio de la Revista Voces en el Fénix, de octubre de 2015:

marco jurídico, los principios y la jurisprudencia provistos por el Sistema Interamericano de protección de los Derechos Humanos lo consagran como el más generoso en materia de libertad de expresión. Al reconocer la doble dimensión de este derecho -individual y social-, la Corte Interamericana de Derechos Humanos sostuvo que es tan importante el conocimiento de la opinión ajena o la información de que disponen otras personas, como el derecho a difundir las propias creencias o informaciones y reafirmó El que cada acto de comunicación implica simultáneamente las dos dimensiones. 
Hessling Herrera, F.D. Derecho a la comunicación, periodismo e interés público: de la OC-5/85 a los problemas éticos actuales. Derecho y Ciencias Sociales. Noviembre 2020 - Abril 2021. No 24 .Pgs 58 -78. ISSN 1852-2971. Instituto de Cultura Jurídica y Maestría en Sociología Jurídica. Facultad de Ciencias Jurídicas y Sociales. Universidad Nacional de La Plata. Argentina.

El reconocimiento de esa doble dimensión de la libertad de expresión -individual y social- está plasmado en el párrafo 30 de la OC-5/85. El detalle sobre cada una de esas dimensiones viene en los párrafos siguientes ${ }^{3}$.

La OC-5/85 reafirmó en varios pasajes ${ }^{4}$, algunos más explícitos que otros, el vínculo cercano que hay entre el ejercicio pleno de la libertad de expresión y la forma de gobierno democrática, recuperando la tradición anglosajona de la noción, aunque complementándola con las miradas de la Europa continental sobre el rol del Estado, más intervencionista y regulador que en el prisma de los norteamericanos. En la América Latina de entonces, mediados de los 80, la democracia era un anhelo que empezaba a tener un casi imperceptible sabor a conquista, puesto que algunos países comenzaban a dejar atrás las cruentas dictaduras que la historiografía luego agrupó en el Plan Cóndor pergeñado por los Estados Unidos -Ecuador recuperó la democracia en el 79, Bolivia en el 82, Argentina en el 83 y Uruguay apenas unos meses antes de la Opinión Consultiva 5/85 (Pasten, 2006)-.

Los parámetros establecidos en esta Opinión Consultiva de la Corte IDH dieron lugar a las interpretaciones posteriores rubricadas en los fallos, que generaron la jurisprudencia interamericana en la materia (Asdrúbal Aguiar, 2007).

De todos modos, los fallos que reseña como jurisprudencia el ex juez de la Corte IDH Asdrúbal Aguiar comienzan luego de otros dos hechos trascendentales en el SIDH: la creación de la Relatoría Especial para la Libertad de Expresión y la posterior Declaración de Principios sobre Libertad de Expresión, elaborada por la primera.

Así lo reseña Santiago Cantón, primer relator que tuvo el ente, quien además resalta otro instrumento, el Informe sobre Desacato $(1994)^{5}$ (en informe de la OEA, 2017):

\footnotetext{
${ }^{3}$ Dicen esos párrafos siguientes del OC: “31. En su dimensión individual, la libertad de expresión no se agota en el reconocimiento teórico del derecho a hablar o escribir, sino que comprende además, inseparablemente, el derecho a utilizar cualquier medio apropiado para difundir el pensamiento y hacerlo llegar al mayor número de destinatarios. Cuando la Convención proclama que la libertad de pensamiento y expresión comprende el derecho de difundir informaciones e ideas "por cualquier... procedimiento", está subrayando que la expresión y la difusión del pensamiento y de la información son indivisibles, de modo que una restricción de las posibilidades de divulgación representa directamente, y en la misma medida, un límite al derecho de expresarse libremente. De allí la importancia del régimen legal aplicable a la prensa y al status de quienes se dediquen profesionalmente a ella". "32. En su dimensión social la libertad de expresión es un medio para el intercambio de ideas e informaciones y para la comunicación masiva entre los seres humanos. Así como comprende el derecho de cada uno a tratar de comunicar a los otros sus propios puntos de vista implica también el derecho de todos a conocer opiniones y noticias. Para el ciudadano común tiene tanta importancia el conocimiento de la opinión ajena o de la información de que disponen otros como el derecho a difundir la propia".

${ }^{4}$ Entre otros, en el párrafo 69: "La libertad de expresión se inserta en el orden público primario y radical de la democracia, que no es concebible sin el debate libre y sin que la disidencia tenga pleno derecho de manifestarse". ${ }^{5}$ Es interesante señalar que ese informe vino luego de una solución amistosa que se consiguió en el caso del periodista argentino Horacio Verbitsky, quien demandó al Estado nacional por haberlo condenado penalmente por
} 
Hessling Herrera, F.D. Derecho a la comunicación, periodismo e interés público: de la OC-5/85 a los problemas éticos actuales. Derecho y Ciencias Sociales. Noviembre 2020 - Abril 2021. No 24 .Pgs 58 -78. ISSN 1852-2971. Instituto de Cultura Jurídica y Maestría en Sociología Jurídica. Facultad de Ciencias Jurídicas y Sociales. Universidad Nacional de La Plata. Argentina.

El camino iniciado por la Corte permitió que con posterioridad a la OC-5/85, en otras tres ocasiones, la CIDH haya tenido la oportunidad de resaltar la importancia del derecho a la libertad de expresión: el Informe sobre Desacato, la creación de la Relatoría Especial de Libertad de Expresión y la Declaración de Principios de Libertad de Expresión. Estas cuatro instancias de defensa, dentro del SIDH, configuran los pilares que sostienen una red de defensa hemisférica, que a lo largo de las décadas ha contribuido significativamente al fortalecimiento de nuestras democracias.

La Relatoría fue creada en las postrimerías del siglo XX. Cantón describe así el contexto que en que surgió:

El origen de la Relatoría fue un diálogo en octubre de 1997, entre el Presidente de Estados Unidos, Bill Clinton, y el Presidente de Argentina, Carlos Menem, en donde a raíz de los ataques contra periodistas, Clinton sugirió la creación de una institución especial encargada de vigilar la libertad de expresión en las Américas. Si bien inicialmente no estaba decidida la forma que debería tener dicha institución, la CIDH rápidamente tomó la iniciativa, y con base en su propia experiencia y sus mandatos, anunció la creación de la Relatoría. Varias organizaciones de derechos humanos y de defensa de la libertad de expresión apoyaron la iniciativa, que rápidamente también obtuvo un apoyo inequívoco por parte de todos los gobiernos de las Américas, durante la Cumbre celebrada en Santiago de Chile en abril de 1998.

La Declaración de Principios sobre Libertad de Expresión, por su parte, fue aprobada por la Comisión Interamericana de Derechos Humanos en octubre de 2000. Consta de trece principios, que no hacen otra cosa que clarificar estándares mínimos de interpretación del artículo 13 de la Convención, ya que hasta entonces los parámetros venían dados sólo por informes de la Comisión u Opiniones Consultivas de la Corte.

\footnotetext{
"desacato", amparándose en el entonces vigente artículo 244 del Código Penal Argentino. No está de más resaltar que el décimo principio de la Declaración de Principios Sobre Libertad de Expresión estipula que "la protección a la reputación debe estar garantizada sólo a través de sanciones civiles, en los casos en que la persona ofendida sea un funcionario o figura pública o particular que se haya involucrado voluntariamente en asuntos de interés público". Propender a la suspensión de las sanciones penales, como la figura del desacato, fue una impronta que vino en el SIDH luego del caso de Verbitsky.
} 
Hessling Herrera, F.D. Derecho a la comunicación, periodismo e interés público: de la OC-5/85 a los problemas éticos actuales. Derecho y Ciencias Sociales. Noviembre 2020 - Abril 2021. No 24 .Pgs 58 -78. ISSN 1852-2971. Instituto de Cultura Jurídica y Maestría en Sociología Jurídica. Facultad de Ciencias Jurídicas y Sociales. Universidad Nacional de La Plata. Argentina.

En los principios de la Declaración quedan claros algunos componentes de lo que ciertos autores llaman hoy en día el "Derecho a la Información" o "a la Comunicación" (Loreti y Lozano, 2014). El tercer principio, por ejemplo, da lugar a lo que se conoce como "habeas data”. El principio cuarto añade el derecho a acceder a la información pública, en manos del Estado, salvo expresas excepciones que deberán estar pautadas por ley interna. El octavo principio estipula el derecho a la reserva de fuentes de los "comunicadores sociales". El décimo principio introduce la noción de "interés público" y la doceavo pauta que deben evitarse los oligopolios y monopolios en los medios de comunicación, debido a que atentan contra la diversidad y pluralidad que amerita toda democracia.

\section{Libertad de Expresión y derecho a la comunicación}

Cabe preguntarse, entonces, qué diferencia el derecho a la comunicación de la libertad de expresión. Lo cierto es que no hay diferencias sustanciales, puesto que lo que intenta abarcar el derecho a la comunicación ya está estipulado en la doble dimensión de análisis que implica la libertad de expresión desde la óptica de los derechos humanos. Doble dimensión, individual y social, y doble dimensión en cuanto al derecho de enunciar y al derecho de las audiencias a ser informadas de modo preciso y transparente.

El hecho de hablar de derecho a la comunicación acaece con mayor profusión en ámbitos académicos que en la doctrina o en los textos jurídicos. Se trata de una denominación más específica sobre el fenómeno que intenta contemplarse, aunque en el fondo no haya ningún ajuste conceptual sobre los alcances de tal derecho (Loreti y Lozano, 2014).

No obstante, el enmiendo denominativo no es menor, puesto que habilita a dejar atrás la asimilación que la doctrina de derechos humanos ha hecho entre libertad de expresión y ejercicio periodístico. En la idea de derecho a la comunicación no se pondera al periodismo por encima del resto de la población, igualmente facultada para expresarse y ser oída, al tiempo que para acceder a la información. Ello, sin dejar de reconocer la particularidad del periodismo a partir del reconocimiento que la Corte IDH había dado a la libertad de expresión: implica ambas dimensiones, la individual de expresarse y la colectiva de la sociedad de recibir información rigurosa. Esta última dimensión, para el caso del periodismo, es un eje rector al momento de determinar la deontología del oficio (volveremos sobre este punto en el apartado 5 de este artículo). 
Hessling Herrera, F.D. Derecho a la comunicación, periodismo e interés público: de la OC-5/85 a los problemas éticos actuales. Derecho y Ciencias Sociales. Noviembre 2020 - Abril 2021. No 24 .Pgs 58 -78. ISSN 1852-2971. Instituto de Cultura Jurídica y Maestría en Sociología Jurídica. Facultad de Ciencias Jurídicas y Sociales. Universidad Nacional de La Plata. Argentina.

\section{Debates a partir de la triangulación entre libertad de expresión, periodismo e interés}

\section{público}

Entre las aristas álgidas alrededor de la triangulación entre libertad de expresión, periodismo e interés público se encuentran algunas de las cuestiones que han venido interpretándose en el SIDH, pero también en otros sistemas de derechos humanos. La cuestión de interés público, sin ir más allá, ha sido especialmente explorada especialmente en Europa, con los casos Axel Springer AG contra Alemania y Von Hannover vs. Alemania, ambos con sentencia el 7 de febrero de 2012. En ambos se sienta posición sobre la idea de "interés general” en tensión con la libertad de expresión, ya que el actor mencionado por el Bild -periódico de los Springer- y los Von Hannover fueron considerados figuras públicas y, por lo tanto, parte del interés público. Por lo tanto, interpretó la Corte Europea de Derechos Humanos en torno a los artículos 8 y 10 de la Convención Europea, las publicaciones al respecto no habían sido extralimitaciones en el ejercicio de la libertad de expresión.

Tomando el caso puntual del fallo en Axel Springer AG contra Alemania, el Anuario de Derecho Público de 2012 de la Universidad Diego Portales ${ }^{6}$ detalla:

El Tribunal consideró que la empresa estuvo en lo correcto al sostener que no existían motivos suficientemente fuertes para mantener a $\mathrm{X}$ [el actor] en el anonimato, y estableció por doce votos contra cinco que hubo una violación del artículo 10 de la Convención sobre libertad de expresión, en perjuicio de la editorial Springer. Al respecto, se estableció que las partes estaban en desacuerdo sobre 'si la interferencia fue necesaria en una sociedad democrática'. Por lo anterior, el Tribunal aplicó el test de proporcionalidad y, además, consideró los siguientes criterios: (a) la contribución a un debate de interés general;(b) qué tan bien conocida es la persona en cuestión y cuál es el tema del informe;(c) la conducta previa de la persona interesada;(d) el método de obtención de la información y su veracidad;(e) el contenido, forma y consecuencias de la publicación; y (f) la gravedad de la sanción impuesta. Como conclusión, se determinó que los motivos invocados por el Estado, aunque relevantes, no eran suficientes para establecer que la interferencia a la empresa de comunicación fuera necesaria en una sociedad democrática.

\footnotetext{
${ }^{6}$ El anuario de la universidad chilena, en esa edición estuvo coordinado por Judith Schönsteiner.
} 
Hessling Herrera, F.D. Derecho a la comunicación, periodismo e interés público: de la OC-5/85 a los problemas éticos actuales. Derecho y Ciencias Sociales. Noviembre 2020 - Abril 2021. No 24 .Pgs 58 -78. ISSN 1852-2971. Instituto de Cultura Jurídica y Maestría en Sociología Jurídica. Facultad de Ciencias Jurídicas y Sociales. Universidad Nacional de La Plata. Argentina.

A la inversa, en el caso de la familia Von Hannover, la Corte Europea de Derechos Humanos no dio lugar al reclamo de los demandantes, quienes habían planteado que su derecho a la vida privada y familiar habían sido vulnerados por publicaciones mediáticas que no habían sido censuradas por los tribunales internos de Alemania. La Corte continental entendió que eran figuras públicas y que en las publicaciones que los implicaban primaba el derecho de las audiencias a informarse sobre sus vidas.

Lo que en el marco europeo se menciona como "interés general" en la doctrina del SIDH es mencionado como "interés público”. En el décimo principio de la Declaración sobre Libertad de Expresión se lee:

Las leyes de privacidad no deben inhibir ni restringir la investigación y difusión de información de interés público. La protección a la reputación debe estar garantizada sólo a través de sanciones civiles, en los casos en que la persona ofendida sea un funcionario público o persona pública o particular que se haya involucrado voluntariamente en asuntos de interés público. Además, en estos casos, debe probarse que en la difusión de las noticias el comunicador tuvo intención de infligir daño o pleno conocimiento de que se estaba difundiendo noticias falsas o se condujo con manifiesta negligencia en la búsqueda de la verdad o falsedad de las mismas.

Anticipándose a interpretaciones muy amplias de ello, en el principio siguiente -onceavo- la Declaración se encarga de enfatizar en que "los funcionarios públicos están sujetos a un mayor escrutinio por parte de la sociedad".

La OC-5/85, por su parte, apenas esboza la cuestión del interés público, aunque sólo para referirse a las restricciones a la libertad de expresión que, dice citando a la Corte Europea de Derechos Humanos, no sólo deben ser "útiles", "racionales" u "oportunas" sino que también deben estar orientadas a "satisfacer un interés público imperativo" (párrafo 46). En cambio, la Corte IDH interpreta que el periodismo se vincula a las ideas de "orden público" y "bien común" (párrafos 64 a 69).

A la luz de esas ideas es que la Corte IDH interpreta en la mencionada OC-5/85 que el periodismo como ocupación liberal vinculada al orden público y al bien común. En el párrafo 70 dice: 
Hessling Herrera, F.D. Derecho a la comunicación, periodismo e interés público: de la OC-5/85 a los problemas éticos actuales. Derecho y Ciencias Sociales. Noviembre 2020 - Abril 2021. No 24 .Pgs 58 -78. ISSN 1852-2971. Instituto de Cultura Jurídica y Maestría en Sociología Jurídica. Facultad de Ciencias Jurídicas y Sociales. Universidad Nacional de La Plata. Argentina.

La libertad de expresión es una piedra angular en la existencia misma de una sociedad democrática. Es indispensable para la formación de la opinión pública. Es también conditio sine qua non para que los partidos políticos, los sindicatos, las sociedades científicas y culturales, y en general, quienes deseen influir sobre la colectividad puedan desarrollarse plenamente. Es, en fin, condición para que la comunidad, a la hora de ejercer sus opciones, esté suficientemente informada. Por ende, es posible afirmar que una sociedad que no está bien informada no es plenamente libre.

Y en el párrafo 75 aclara sobre su interpretación de la relación entre libertad de expresión y periodismo:

El ejercicio del periodismo profesional no puede ser diferenciado de la libertad de expresión, por el contrario, ambas cosas están evidentemente imbricadas, pues el periodista profesional no es, ni puede ser, otra cosa que una persona que ha decidido ejercer la libertad de expresión de modo continuo, estable y remunerado. Además, la consideración de ambas cuestiones como actividades distintas, podría conducir a la conclusión de que las garantías contenidas en el artículo 13 de la Convención no se aplican a los periodistas profesionales.

Es a partir de esa interpretación entre orden público-bien común (diremos "interés público"), libertad de expresión y periodismo que la Corte IDH rechaza la colegiación de periodistas. En ese sentido, aunque se admite que la colegiación sirve como modo de regular otras profesiones liberales, como la abogacía y la medicina, se asegura que el caso del periodismo es particular puesto que "el ejercicio del periodismo, por tanto, requiere que una persona se involucre en actividades que están definidas o encerradas en la libertad de expresión garantizada en la Convención" (párrafo 72), mientras que "el ejercicio del derecho o la medicina -es decir, lo que hacen los abogados o los médicos- no es una actividad específicamente garantizada por la Convención".

De acuerdo con la interpretación de la Corte IDH en su OC-5/85, entonces, el periodismo es la única profesión liberal que se monta sobre un derecho humano fundamental, por la facultad de las personas de recibir un servicio de información logrado, responsable y ético. Señala la Opinión Consultiva en su párrafo 71: 
Hessling Herrera, F.D. Derecho a la comunicación, periodismo e interés público: de la OC-5/85 a los problemas éticos actuales. Derecho y Ciencias Sociales. Noviembre 2020 - Abril 2021. No 24 .Pgs 58 -78. ISSN 1852-2971. Instituto de Cultura Jurídica y Maestría en Sociología Jurídica. Facultad de Ciencias Jurídicas y Sociales. Universidad Nacional de La Plata. Argentina.

Dentro de este contexto el periodismo es la manifestación primaria y principal de la libertad de expresión del pensamiento y, por esa razón, no puede concebirse meramente como la prestación de un servicio al público a través de la aplicación de unos conocimientos o capacitación adquiridos en una universidad o por quienes están inscritos en un determinado colegio profesional, como podría suceder con otras profesiones, pues está vinculado con la libertad de expresión que es inherente a todo ser humano.

La emergencia de internet, a mediados de los 90, aparejó grandes cambios en la práctica periodística en particular y, en general, en la circulación de la información y los flujos de comunicación. La proliferación a nivel mundial de la red habilitó un espacio de intercambios que trascendió lo que hasta entonces se había conocido como medios de comunicación masiva. Desde la aparición de internet, cada persona, y personas jurídicas inclusive, pueden tener una identidad en línea, pueden publicar y expresarse de modo sistemático con aspiraciones de llegar a grandes audiencias, sobre todo desde la aparición de las redes sociales (Calvo y Aruguete, 2020).

Por lo tanto, si bien las y los periodistas siguen siendo los profesionales en "buscar" y "difundir" información, el ejercicio sistemático de la libertad de expresión, la ejecución "continua y estable" de tal derecho, en palabras de la OC-5/85 (párrafo 74), ya no es propia sólo del ámbito reporteril.

Periodismo en la contemporaneidad: del corset a la distinción con respecto a la libertad de expresión como derecho colectivo

Hagamos una primera aclaración: se considera que el debate de si el periodismo es un oficio o una profesión es tangencial. La división entre oficio y profesión está sustentada en las titulaciones universitarias, es decir, los que lo consideran un oficio dicen que no hacen falta menciones académicas para trabajar como periodista y los que lo consideran una profesión postulan exactamente lo opuesto. Lo que se sugiere es que el periodismo es una práctica que se aprende en el hacer -característica de los oficios- y que se sostiene sólo con profesionalismo cualidad en el método de trabajo-. Es decir, el periodismo se aprende como un oficio y amerita necesariamente profesionalismo, pensando este último como una virtud en el modo de trabajo y no como un grado que se obtiene a través de títulos académicos. 
Hessling Herrera, F.D. Derecho a la comunicación, periodismo e interés público: de la OC-5/85 a los problemas éticos actuales. Derecho y Ciencias Sociales. Noviembre 2020 - Abril 2021. No 24 .Pgs 58 -78. ISSN 1852-2971. Instituto de Cultura Jurídica y Maestría en Sociología Jurídica. Facultad de Ciencias Jurídicas y Sociales. Universidad Nacional de La Plata. Argentina.

Entonces, para salir de ese atolladero que opone oficio a profesión diremos que el periodismo se define en tres sentidos: como discurso, como método y como relación social de producción. En algún sentido, definirlo como discurso y como método es parte de la mirada moderna sobre el conocimiento -Descartes configuró igual a la ciencia-, en coherencia con su surgimiento como oficio-profesión liberal. La mirada sobre la práctica periodística como relación social de producción habilita a observar, además, que no es una práctica intelectual abstraída de las tensiones económicas que la circundan.

\section{a. Como discurso}

Pensar el periodismo como discurso social específico (Van Dijck, 2005), es decir como un constructo con ciertas características textuales pero también con determinadas dinámicas de interacción social, posibilita que se recupere la importancia del periodismo como profesiónoficio liberal, es decir, como elemento constituyente de una sociedad democrática. Esto se vincula directamente con la ya mencionada dimensión social de la libertad de expresión, ya que el periodismo como discurso social específico tiene el deber de hacerlo efectivo. La idea de que el periodismo está montado sobre la libertad de expresión, central en la doctrina de la Corte IDH, puede desplazarse hacia una relación de vinculaciones mutuas más que de montajes. De hecho, ni siquiera cronológicamente la libertad de expresión E es preminente al periodismo, que se ejerce desde antes que existiese la noción de libertad de expresión (en "1. De la inviolabilidad parlamentaria al libre mercado de ideas" de este artículo). El periodismo no se para sobre la libertad de expresión sino que recibe de ésta, en tanto que derecho humano, los cimientos de su deontología.

Lo que se quiere enfatizar es que, en tanto que discurso social específico, el periodismo genera determinadas expectativas en la sociedad, por ello, para ejercerlo a la altura de esas expectativas conviene aceptar como elementos nodales de la ética periodística los desarrollos teóricos sobre libertad de expresión.

En la actualidad, la información no circula nada más que a través de medios tradicionales de comunicación masiva, y ni siquiera todo lo que se produce en ellos es de carácter periodístico; sin embargo, el periodismo concita ciertas expectativas sociales a partir de valores como la credibilidad, la pretensión de verdad, la rigurosidad y la exactitud en la descripción de los hechos, etc. Para que el ejercicio sostenga esos valores conviene que las y los periodistas consideren como un deber garantizar la más acabada realización de la dimensión social de la 
Hessling Herrera, F.D. Derecho a la comunicación, periodismo e interés público: de la OC-5/85 a los problemas éticos actuales. Derecho y Ciencias Sociales. Noviembre 2020 - Abril 2021. No 24 .Pgs 58 -78. ISSN 1852-2971. Instituto de Cultura Jurídica y Maestría en Sociología Jurídica. Facultad de Ciencias Jurídicas y Sociales. Universidad Nacional de La Plata. Argentina.

libertad de expresión. En lenguaje llano, podría decirse que el periodismo debe fungir como guardián del interés público.

\section{b. Como método}

En segundo lugar, el periodismo como método implica reconocer que para ejercerlo hay una lex artis, concepto que se define como el manejo correcto de un conjunto de técnicas para desempeñar un oficio, profesión o arte. Obviando los rigores de la discusión conceptual en términos filosóficos, podría decirse que la lex artis es la figura opuesta a la mala praxis. Contrariamente con lo que sucede en el periodismo, en otras profesiones-oficios liberales como la medicina la mala praxis puede significar la pérdida de la matrícula para el ejercicio profesional.

La lex artis del periodismo se sintetiza en los códigos de ética periodística, entre los que hay de índole nacional e internacional según la organización de reporteros que lo haya promovido. Esos códigos de ética, sin embargo, en términos jurídicos no generan ninguna vinculación directa. En este punto se ve que para que los estándares de la libertad de expresión como derecho humano guíen la práctica periodística se necesitan instrumentos con vinculación jurídica para la deontología, para el deber-hacer.

Entre buenas prácticas periodísticas pueden mencionarse, también como parte de los estándares desarrollos en el SIDH, que el derecho a réplica debe ser ofrecido, que se debe consultar partes y contrapartes tanto como diversidad y variedad de fuentes, al tiempo que se debe distinguir en la enunciación las opiniones e interpretaciones de la exposición de los hechos y datos.

\section{c. Como relación social de producción}

En último lugar, el hecho de asumir al periodismo como una relación social de producción permite darle anclaje tanto al discurso como al método. Cada producción periodística puntual está situada, se inscribe en un determinado contexto económico. Esa dimensión es determinante para analizar la producción de modo integral, puesto que según la relación social de producción en donde se inscriba tal o cual trabajo periodístico serán distintos los resultados, la forma de presentarlos y las intenciones.

En líneas generales, a partir de la flexibilización laboral que trajo el neoliberalismo y del avance de las nuevas tecnologías de la información y la comunicación, el periodismo ha pasado a ejercerse cada vez más de modo freelancer, es decir, como trabajadores independientes que venden sus producciones a los medios o a las agencias de noticias. Asimismo, ha proliferado el 
Hessling Herrera, F.D. Derecho a la comunicación, periodismo e interés público: de la OC-5/85 a los problemas éticos actuales. Derecho y Ciencias Sociales. Noviembre 2020 - Abril 2021. No 24 .Pgs 58 -78. ISSN 1852-2971. Instituto de Cultura Jurídica y Maestría en Sociología Jurídica. Facultad de Ciencias Jurídicas y Sociales. Universidad Nacional de La Plata. Argentina.

cuentapropismo emprendedor, con multiplicidad de pequeños medios -páginas web en su mayoría-. Ambos crecimientos -los freelancers y los emprendedores- fueron en detrimento de las situaciones de empleo en relación de dependencia. Además, se ejerce el periodismo de modo militante, en espacios de comunicación autogestiva, alternativa y comunitaria.

Uno/a mismo/a periodista puede trabajar como asalariado/a para un medio y al mismo tiempo vender notas como freelancer, o puede tener su pequeño emprendimiento de comunicación y formar parte de una cooperativa de contenidos informativos. En cada caso puntual, aunque se trate de la misma persona, los resultados de su producción serán distintos, porque reflejarán la relación social de producción en la que ese contenido está inscripto. La relación social de producción, entonces, no es una variable más, es una condicionante fundamental para el resultado de lo que se elabora y publica.

Este punto, vinculado a los dos anteriores, es fundamental para reabrir la discusión que la Corte IDH zanjó en su OC-5/85 al respecto de la colegiación obligatoria de periodistas. Si muchos/as periodistas han dejado de estar en relación de dependencia sin pasar a ser patronales que emplean a otros, la vigencia de la organización sindical queda vetusta, en tanto esa gran porción de reporteros quedaría fuera de su contención. La vinculación con las expectativas sociales en torno al discurso periodístico y la lex artis del método conducen a pensar que, desbordada la forma de organización sindical, sería útil volver a pensar formas de organización colegiada, sin que la colegiación se asimile al título universitario.

Un colegio de periodistas contendría la diversidad de relaciones sociales de producción que existen hoy en día para los trabajadores del periodismo, serviría como resguardo para ellos (lo que antes se veía como el montaje del periodismo sobre la libertad de expresión) y, mediante tribunales de ética vinculantes, garantizaría el deber de ejercerlo con la ética periodística que se deriva de la deontología influenciada por la libertad de expresión. Colegiación a través de deontología en el ejercicio, lex artis, matriculación para evitar que de un momento a otro las empresas de medios prescindan de periodistas porque prioricen la producción de contenidos informativos sin rigor, y regulación para que los códigos de ética dejen de ser meramente referenciales.

\section{Deontología periodística e interés público}

A partir del deber que representa para el periodismo el hecho de que las audiencias tengan derecho a informarse con datos rigurosos, se abre un arco de discusión al respecto de una noción imprescindible para pensar el tipo de información que sería imprescindible para la sociedad: la 
Hessling Herrera, F.D. Derecho a la comunicación, periodismo e interés público: de la OC-5/85 a los problemas éticos actuales. Derecho y Ciencias Sociales. Noviembre 2020 - Abril 2021. No 24 .Pgs 58 -78. ISSN 1852-2971. Instituto de Cultura Jurídica y Maestría en Sociología Jurídica. Facultad de Ciencias Jurídicas y Sociales. Universidad Nacional de La Plata. Argentina.

noción de interés público. Determinar el interés público se torna de capital importancia, puesto que si no se podría considerar que cualquier información tiene el mismo valor.

Lo primero que conviene aclarar en este caso es que el interés público no es un compartimiento estanco que haya que consultar antes de ejercer el periodismo, más bien se trata de una construcción histórica que se va modificando a medida que las tensiones sociales se manifiestan y amplifican en instancias tales como las redes sociales y los medios tradicionales de comunicación para las masas (Calvo y Aruguete, 2020). Por ejemplo, nadie en Argentina en el 2000 se hubiese imaginado que en 2020 ninguna placa televisiva rubricaría el comportamiento diario del "riesgo país". Igual con la cotización del dólar: en los 90 hubiese sido imposible creer que eso formara parte del interés público.

Entonces, ¿cómo se determina el interés público? Es imposible establecerlo de modo estandarizado, al contrario, se debe tomar en consideración las situaciones actuales de tal o cual sociedad. Sin embargo, también puede decirse que el interés público, en sociedades democráticas y/o pretendidamente igualitarias, siempre está guiado por la información pública, es decir, por la transparencia de los actos de gobierno y las decisiones estatales que implican a la sociedad como un conjunto integrado dentro de un determinado territorio.

De todas maneras, el interés público nunca está escrito ni preestablecido sino que se va delimitando con la práctica misma de una determinada sociedad, en un determinado momento histórico. En esa dinámica, el contenido que se genera a través de los medios de comunicación para las masas es de vital importancia. El periodismo, como una parte específica de esos contenidos mediáticos, es todavía más relevante en ese sentido.

Así, de la misma forma que puede verse en el periodismo la encarnación de las dos dimensiones que la doctrina de derechos humanos le atribuye a la libertad de expresión, también en ese oficio puede verse una doble relación con el interés público: por una parte, los periodistas deben mantenerse sensibles a las construcciones históricas de las sociedades en las que intervienen para reconocer los contornos del interés público, y por otra parte deben asumirse como coconstructores del mismo.

La consciencia sobre esto último facilita dejar definitivamente de lado las pretensiones de objetividad: si bien el discurso periodístico, igual que el científico, opera sobre datos objetivos, se trata de planteos subjetivos que buscan intervenir en la sociedad generando, confrontando o fortaleciendo ideas. El periodismo es un privilegiado co-constructor del interés público, por eso debe reconocerse como tal y asumir como un deber la dimensión colectiva de la libertad de 
Hessling Herrera, F.D. Derecho a la comunicación, periodismo e interés público: de la OC-5/85 a los problemas éticos actuales. Derecho y Ciencias Sociales. Noviembre 2020 - Abril 2021. No 24 .Pgs 58 -78. ISSN 1852-2971. Instituto de Cultura Jurídica y Maestría en Sociología Jurídica. Facultad de Ciencias Jurídicas y Sociales. Universidad Nacional de La Plata. Argentina.

expresión, el derecho de las audiencias a estar informadas con datos precisos, rigurosos y fidedignos.

\section{Deontología periodística y método de trabajo}

Además de la atención para detectar los alcances epocales del interés público y de la conciencia sobre el rol de co-constructures del mismo, las y los periodistas deben necesariamente guiarse por un método de trabajo que garantice que la búsqueda y generación de información rigurosa se realizó siguiendo la "lex artis" -lo contrario de la mala praxis, es decir el conjunto de técnicas que se consideran buenas prácticas- que corresponde al oficio.

En este caso conviene detenerse en una aclaración: el autor de ete artículo considera falsa la dicotomía que divide las interpretaciones sobre el ejercicio periodístico entre oficio y profesión, en cambio, se las propone complementarias. Es un oficio, porque no depende de ninguna titulación universitaria ni de grado académico alguno para poder desempeñarlo, pero que para hacerlo correctamente se debe ejecutarlo con profesionalismo. Es un oficio que deontológicamente debe ser practicado con profesionalismo. En ese sentido, se lo agrupa dentro de las profesiones liberales clásicas, la abogacía y la medicina.

Ese profesionalismo está dado justamente por la identificación de un método de trabajo que, a su vez, está pautado por la memoria histórica de quienes han venido desempeñando por siglos el oficio. El método debería estar reflejado en los códigos de ética periodística, que deberían dejar de ser meramente referenciales y convertirse en vinculantes, porque tal y como están dadas las cosas ahora, cualquier periodista incumple los códigos y no recibe sanción alguna.

Para hacer este último cambio habría que dejar de considerar la asimilación entre libertad de expresión y periodismo en los términos que los ha sugerido en 1985 la Corte IDH y empezar a habilitar formas de autorregulación del oficio, igual que sucede con las otras profesiones liberales que están colegiadas. El periodismo necesita esas formas de autorregulación porque necesita delimitarse de otras formas de ejercicio sistemático y remunerado de libertad de expresión, como los influencers y youtubers, y porque requiere resguardo para la estabilidad laboral.

En un ejemplo burdo se podría decir que cualquier puede, si tiene capital suficiente, montar una clínica. Sin embargo, para que sea legal, necesitaría contar con médicos, porque si sólo contrata a herboterapeutas, aunque estos cumplan el cometido de sanar, sería ilegal en tanto que clínica. En cambio, cualquier puede montar una empresa mediática y prescindir de contratar periodistas. Algo similar puede decirse del derecho humano de acceso a la justicia, el cual sólo 
Hessling Herrera, F.D. Derecho a la comunicación, periodismo e interés público: de la OC-5/85 a los problemas éticos actuales. Derecho y Ciencias Sociales. Noviembre 2020 - Abril 2021. No 24 .Pgs 58 -78. ISSN 1852-2971. Instituto de Cultura Jurídica y Maestría en Sociología Jurídica. Facultad de Ciencias Jurídicas y Sociales. Universidad Nacional de La Plata. Argentina.

se puede materializar efectivamente dentro del sistema judicial a través de abogados, a raíz de que son los únicos que tienen "legitimidad procesal".

Con la misma óptica que los ejemplos anteriores, que reflejan mecanismos de autorregulación y resguardo corporativo, el periodismo debe replantearse maneras de organizarse que permitan delimitar las buenas prácticas de la mala praxis, la deontología de la inescrupulosidad y las particularidades del discurso periodístico con relación a otros discursos mediáticos, ni más ni menos legítimos en términos de libertad de expresión, aunque con diferentes expectativas sociales que las que causa el periodismo.

\section{Conclusiones}

Tomando en cuenta que el desarrollo de los instrumentos y jurisprudencia en el SIDH sobre libertad de expresión y su relación con el periodismo y el interés público ha venido delimitado por los cimientos dados por la OC-5/85 se considera inminente una actualización a través de la misma vía -una Opinión Consultiva-, que incluya las particularidades, a todo orden, de la influencia de los flujos informativos a partir de la irrupción de internet y de los cambios en la circulación, producción y recepción de la información que se vienen experimentando.

En particular sobre el ejercicio periodístico, como se ha señalado más arriba, las características que distinguen al profesional, según el texto de 1985, son el ejercicio "continuo, estable y remunerado" de la libertad de expresión. Sacando la cuestión de la remuneración, aunque podría ser incluida para ciertos trabajos -publicistas, influencers o community managers, por ejemplo-, el ejercicio continuo y estable de ese derecho, buscando, recibiendo y difundiendo información a la mayor cantidad de personas posible, se ha tornado una práctica habitual para grandes mayorías de la población.

De igual manera, la afirmación de la OC-5/85 de que "son los medios de comunicación social los que sirven para materializar el ejercicio de la libertad de expresión", suena vigente y al mismo tiempo escueta sobre lo que internet representa, ya que, en palabras de Esteban Lescano, dicha red es una "plataforma para la actividad económica, el desarrollo humano y la participación ciudadana”.

Sucede que, tal y como lo ha planteado la Corte IDH en su interpretación primigenia y todavía señera de 1985, el periodismo no puede ser disociado de la libertad de expresión ni del interés público. Sin embargo, no toda expresión en el espacio público -internet incluido- es periodismo, ni todo trabajo en los medios o redes sociales es de periodista, ni toda publicación mediática o 
Hessling Herrera, F.D. Derecho a la comunicación, periodismo e interés público: de la OC-5/85 a los problemas éticos actuales. Derecho y Ciencias Sociales. Noviembre 2020 - Abril 2021. No 24 .Pgs 58 -78. ISSN 1852-2971. Instituto de Cultura Jurídica y Maestría en Sociología Jurídica. Facultad de Ciencias Jurídicas y Sociales. Universidad Nacional de La Plata. Argentina.

en redes sociales está especialmente ocupada en el interés público, como sí deben estar las publicaciones consideradas periodísticas.

Por todo lo dicho anteriormente y sin pretender zanjar esas discusiones, al contrario, tratando de que los debates aparentemente sellados por la intelectualidad jurídica, periodística y académica se reabran constantemente, cerramos sugiriendo algunas conclusiones preliminares:

- El/la periodista debe trabajar con profesionalismo, respetando un método y el horizonte de entender y al mismo tiempo ser co-constructor del interés público. Esa doble función de entender/construir el interés público caracteriza al oficio, por eso se pueden reconocer determinadas expectativas sociales distintivas sobre el periodismo.

- El/la periodista puede cometer errores involuntarios, esos no son fake news. Sin embargo, sean errores o mala praxis intencional, nada implica responsabilidades hasta tanto los códigos de ética no funcionen como elementos vinculantes en términos formales.

- En los códigos de ética periodística deben reflejarse las buenas prácticas del oficio a partir de las cuales se garantiza el derecho de las audiencias a recibir información fidedigna. Esas buenas prácticas deben partir de la idea que la información forma parte de un derecho humano y no que es una mercancía, por lo tanto, deben estar al servicio del interés público.

- La doctrina del SIDH debe actualizarse en relación con su concepción sobre el periodismo, asumiendo que si bien es una profesión liberal vinculada con un derecho humano, no son los únicos que pueden ejercerlo y por lo tanto no se puede reducir toda interpretación y regulación sobre la profesión como una interpretación o regulación a la libertad de expresión en su conjunto.

\section{Bibliografía}

Aguiar, Asdrúbal. (2007) Jurisprudencia interamericana sobre libertad de expresión y derecho a réplica. Disponible en: http://www.corteidh.or.cr/tablas/r37840.pdf.

Calvo, Ernesto y Aruguete, Natalia (2020) Fake news, trolls y otros encantos. Buenos Aires, Siglo XXI Editores.

CIDH. Relatoría Especial para la Libertad de Expresión de la OEA. Libertad de expresión e internet. http://www.oas.org/es/cidh/expresion/docs/informes/2014_04_08_Internet_WEB.pdf.

Climent Gallart, Jorge Antonio. (2016). Análisis de los orígenes de la libertad de expresión como explicación de su actual configuración como garantía institucional. Revista 
Hessling Herrera, F.D. Derecho a la comunicación, periodismo e interés público: de la OC-5/85 a los problemas éticos actuales. Derecho y Ciencias Sociales. Noviembre 2020 - Abril 2021. No 24 .Pgs 58 -78. ISSN 1852-2971. Instituto de Cultura Jurídica y Maestría en Sociología Jurídica. Facultad de Ciencias Jurídicas y Sociales. Universidad Nacional de La Plata. Argentina.

Boliviana de Derecho (22), 236-253. ISSN 2070-8157. Disponible en: http://www.scielo.org.bo/pdf/rbd/n22/n22_a11.pdf.

Faundez Ledesma, Héctor. (2003). (3ra edición). El sistema interamericano de protección de los derechos humanos. Aspectos institucionales y procesales. San José de Costa Rica: Edit. Instituto Interamericano de Derechos Humanos.

Faundez Ledesma, Héctor. (2004). Introducción y Conclusión de Los límites de la libertad de expresión. Disponible en: https://archivos.juridicas.unam.mx/www/bjv/libros/4/1540/2.pdf https://archivos.juridicas.unam.mx/www/bjv/libros/4/1540/9.pdf.

Federici, Silvia (2020). Calibán y la bruja. Argentina: Tinta Limón Ediciones.

Lippmann, Walter. (2003). La opinión pública. Cuadernos de Langre, colección: Inactuales.

Loreti, Damián y Lozano, Luis. (2014). El derecho a comunicar. Los conflictos en torno a la libertad de expresión en las sociedades contemporáneas. Buenos Aires: Siglo XXI Editores.

Loreti, Damián y Lozano, Luis (Coord.). (2015). Revista Voces en el Fénix (49), ISSN 18538819. Facultad de Ciencias Económicas, Universidad de Buenos Aires.

Mill, Jonh Stuart. (2010). Sobre la libertad. Buenos Aires: Prometeo.

Pasten, Gustavo. (2006). Seguridad regional en el proceso de integración: Plan Cóndor (antecedente de la integración del Cono Sur). Repuesto de: http://www.iri.edu.ar/publicaciones_iri/IRI\%20COMPLETO\%20-\%20PublicacionesV05/Publicaciones/cd\%20III\%20Congreso/PONENCIAS\%202006/p\%20pasten\%20gu stavo.pdf.

Anuario de Derecho Público de 2012 de la Universidad Diego Portales. Revisión de la jurisprudencia del Tribunal Europeo de Derechos Humanos en el 2012. Disponible en: http://derecho.udp.cl/wp-content/uploads/2016/08/024 aranis otros.pdf.

Secretaría General de la OEA. (2017). Libertad de expresión: A 30 años de la Opinión Consultiva sobre la colegiación de periodistas. Colombia. Disponible en: http://www.oas.org/es/cidh/expresion/docs/publicaciones/OC5_ESP.PDF.

Van Dijck, Teun. (2005). Estructuras y funciones del discurso. México: Siglo XXI Editores. 